\title{
Shared decision-making in the People's Republic of China: current status and future directions
}

\author{
This article was published in the following Dove Press journal: \\ Patient Preference and Adherence \\ 6 August 2015 \\ Number of times this article has been viewed
}

\author{
Rongchong Huang' \\ Michael R Gionfriddo² \\ Lizhi Zhang ${ }^{3}$ \\ Aaron L Leppin ${ }^{2}$ \\ Henry H Ting ${ }^{4}$ \\ Victor M Montori ${ }^{5}$ \\ 'Department of Cardiology, The First \\ Affiliated Hospital of Dalian Medical \\ University, Dalian, Liaoning, People's \\ Republic of China; ${ }^{2}$ Knowledge \\ and Evaluation Research Unit and \\ Mayo Graduate School, ${ }^{3}$ Division of \\ Anatomic Pathology, Department of \\ Laboratory Medicine and Pathology, \\ ${ }^{4} \mathrm{New}$ York-Presbyterian Hospital and \\ Healthcare System, The University \\ Hospital for Columbia and Cornell, \\ New York, NY, ${ }^{5}$ Knowledge and \\ Evaluation Research Unit and Division \\ of Endocrinology, Mayo Clinic, \\ Rochester, MN, USA
}

Background: Severe insufficiencies in the supply and inequities in the distribution of health care professionals, facilities, and services create conditions for limited quality of care and lack of trust - even violent conflict - between clinicians and patients in the People's Republic of China. Alongside structural reform, shared decision-making (SDM) may help meet the needs and advance the goals of each patient. Little is known, however, about the realities and opportunities for SDM in the People's Republic of China.

Methods: To identify reports of SDM in the People's Republic of China, we used multiple sources, including: several databases, searched in English and Chinese, online journals, and clinical trial registries. In addition, we contacted experts in the field to identify any articles missed through our other search strategies. We included all trials and surveys reporting on SDM in Chinese patients. We summarized these studies by describing them with particular attention to reports of patient decisional preference and of the impact of SDM interventions on outcomes in Chinese patients.

Results: We identified five surveys examining patient preference for SDM and nine studies examining constructs related to SDM in Chinese patients, but none involving patients in Mainland China. We could not find any reports of development, testing, or implementation of SDM tools for patients in Mainland China.

Conclusion: The research on SDM in the People's Republic of China is limited, with almost no direct evidence to inform clinical policies or implementation. Although multiple barriers are apparent, the value of implementing, testing, and disseminating effective SDM in the People's Republic of China in terms of patient experience and outcomes demands urgent realization.

Keywords: shared decision-making, the People's Republic of China, patient-centered care

\section{Introduction}

Shared decision-making (SDM) refers to the work that patients and physicians do together to arrive at a medical decision that reflects the best available research evidence and the preferences and values of the informed patient. The process used to arrive at this decision - sharing information, collaborating and deliberating about the options, and deciding ${ }^{1}$ - requires physicians to respect patients and acknowledge the areas about which patients have particular expertise (eg, information about their context, values, and preferences). It also involves some degree of support for patient autonomy and self-efficacy so that they, the patients, are able to take action and face any intended or unintended consequences.

Many decisions in medicine involve uncertainty about which treatment is better. This uncertainty arises from gaps in the evidence or variation in preferences about closely matched alternatives as well as the effects on individuals. SDM seeks to arrive at the best option for a specific patient, with the physician often leading the conversation and empathically engaging the patient to the extent they want to engage
Correspondence: Rongchong Huang The First Affiliated Hospital of Dalian Medical University, 222 Zhongshan Road, Xigang District, Dalian City I I60 I I, Liaoning Province, People's Republic of China

Tel +8641 I 83635963 Extension 7127

Fax +86 I88 4II 2000

Email rchuang@dlmedu.edu.cn
Patient Preference and Adherence 20|5:9 | |29-|| |4| 1129

Dovepress

http://dx.doi.org/10.2147/PPA.S82110 (c) (i) (5) 2015 Huang et al. This work is published by Dove Medical Press Limited, and licensed under Creative Commons Attribution - Non Commercial (unported, v3.0) BY NC License. The full terms of the License are available at http://creativecommons.org/licenses//by-nc/3.0/. Non-commercial uses of the work are permitted without any further permission from Dove Medical Press Limited, provided the work is properly attrbuted. Permissions beyond the scope of the License are administered by Dove Medical Press Limited. Intormation on
how to request permission may be found at: http://www.dovepress.com/permissions.php 
and participate in the process. This approach differs significantly from traditional practices, in which physicians often act in a paternalistic and expedient fashion, deciding for their patients.

This would not be problematic if fateful decisions were technical in nature (ie, not sensitive to values and preferences, eg, which size stent to use), if physicians and patients shared values and preferences, and if lack of patient involvement was inconsequential. Starting in North America and Europe, medicine has been moving away from paternalism and toward SDM, with patients playing a more important role in their own medical care. ${ }^{2}$

A key component of SDM is trust. ${ }^{3}$ A physician must respect the patient, their goals and preferences, which might improve patient's trust; ${ }^{4}$ this respect must arise from a physician's ethical responsibility and training and, in some cases, as a direct consequence of a long-standing relationship with the patient. ${ }^{5}$ Physicians' respect should also manifest as restraint in leading the patient to a particular option and as support as patients struggle to overcome the power gradient between patients and clinicians to make their views known. ${ }^{6}$

Trust is an essential ingredient toward a productive and therapeutic patient-clinician relationship. There is a "trust crisis" in Chinese health care which manifests most notably as violence perpetrated by patients and families toward medical staff. ${ }^{7}$ Although this is not unique to the People's Republic of China, ${ }^{8}$ the magnitude and widespread nature of this crisis argues strongly for innovative solutions. Among those solutions, embedded in urgent structural reform of health care in the People's Republic of China, are those that directly target the patient-clinician interaction. SDM may contribute to improving the trust between patients and clinicians, ${ }^{9}$ while translating evidence into patient-centered care. ${ }^{10}$ Yet, all these views about SDM come from literature describing and analyzing clinical care decisions in North America, Europe, and Australia. Yet, little is known about the state of research and practice of SDM in Mainland China. In this article, we will examine this opportunity, review what is known about SDM in the People's Republic of China, and identify areas in need of further work.

\section{Methods}

\section{Literature identification}

We designed and conducted a search strategy using methods recommended by the Institute of Medicine, ${ }^{11}$ which includes a search of several databases including: PubMed, Scopus, Ovid MEDLINE, Ovid EMBASE, Ovid EBM Reviews CENTRAL, CINAHL, and Ovid PsycInfo. We also searched several Chinese databases including: Wanfang, CNKI, SinoMed, NSTL, CSCD, CBMdisc, and Science and technology magazine online. The databases were searched from the time of their inception to 2014. The initial electronic search strategy was supplemented by screening of reference lists from eligible studies. In addition, we reviewed the reference lists from reviews of the topic. There were no language restrictions. The subject terms or keywords used to retrieve the literature denoted the concepts of SDM (including decision-making), SDM tools (eg, decision aid), and in the People's Republic of China.

\section{Article selection}

Eligible studies were about SDM in Chinese patients, with either observational or experimental designs. Two reviewers working independently selected eligible studies.

\section{Data collection}

We collected the general characteristics of each study (authorship, date of publication, design), methodological details (eg, for surveys, sample size, target participants response rate; for experimental studies, design, interventions and control, primary endpoint), and pertinent results. Data extraction was completed independently and in duplicate.

\section{Analysis}

Given the paucity and inconsistency of available studies, we performed a descriptive analysis.

\section{Results}

We identified five surveys examining patient preference for SDM and nine studies examining constructs related to SDM (Tables 1 and 2). We describe these studies grouped by type.

\section{Shared decision-making in the People's Republic of China - patient preferences for participation}

We found one survey about the SDM preferences of patients from the Mainland China. ${ }^{12}$ This report, published in Chinese, included a survey of 565 patients (response rate 94\%) receiving care at a large teaching hospital in Western China. Although respondents were representative of the general population in terms of sex and occupation, they were younger, more educated, and were enrolled in commercial health insurance. Of those, $68 \%$ had some knowledge of their disease, $93 \%$ were willing to participate in clinical decisionmaking, 89\%-95\% wanted physicians to seek their opinion 


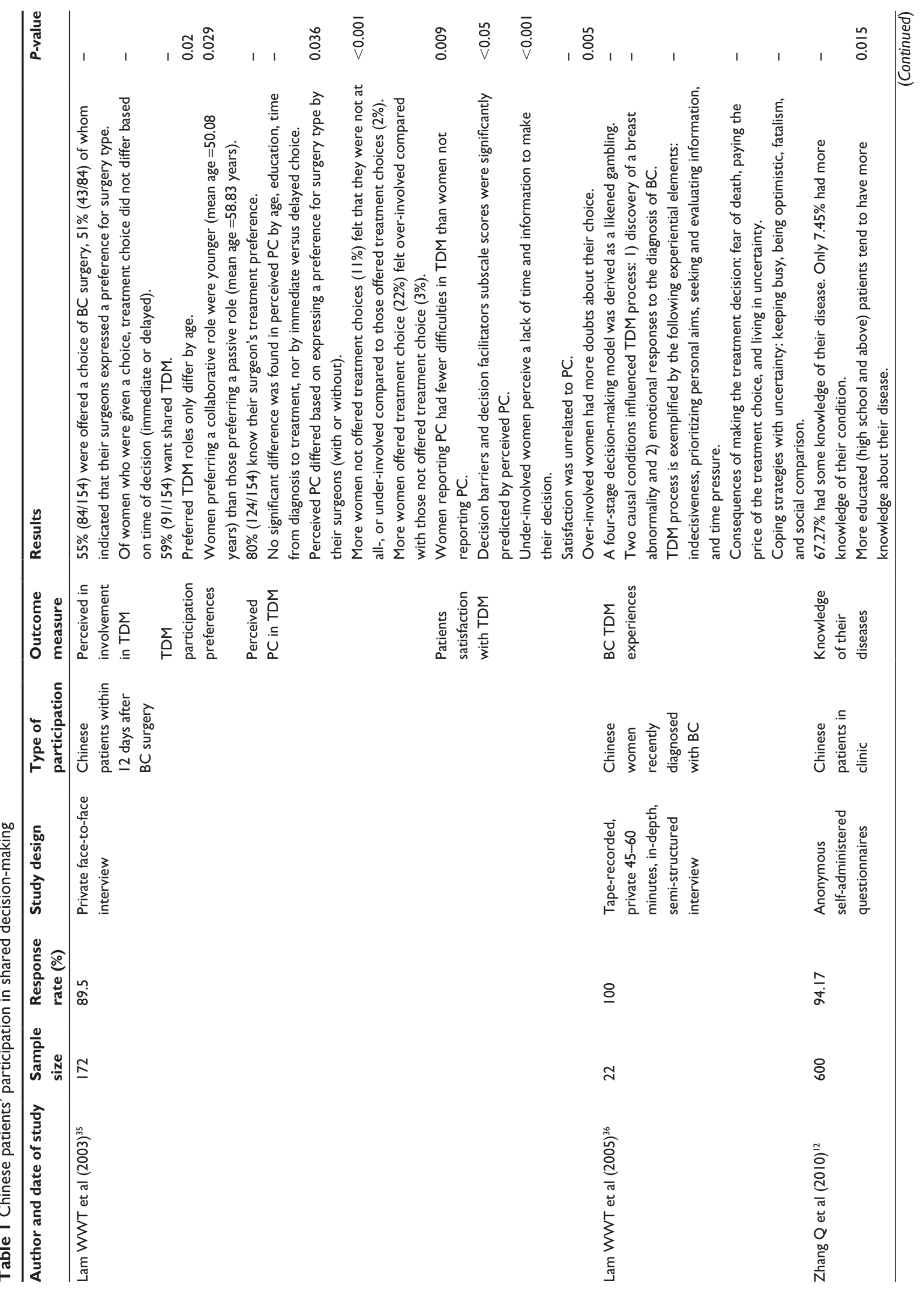




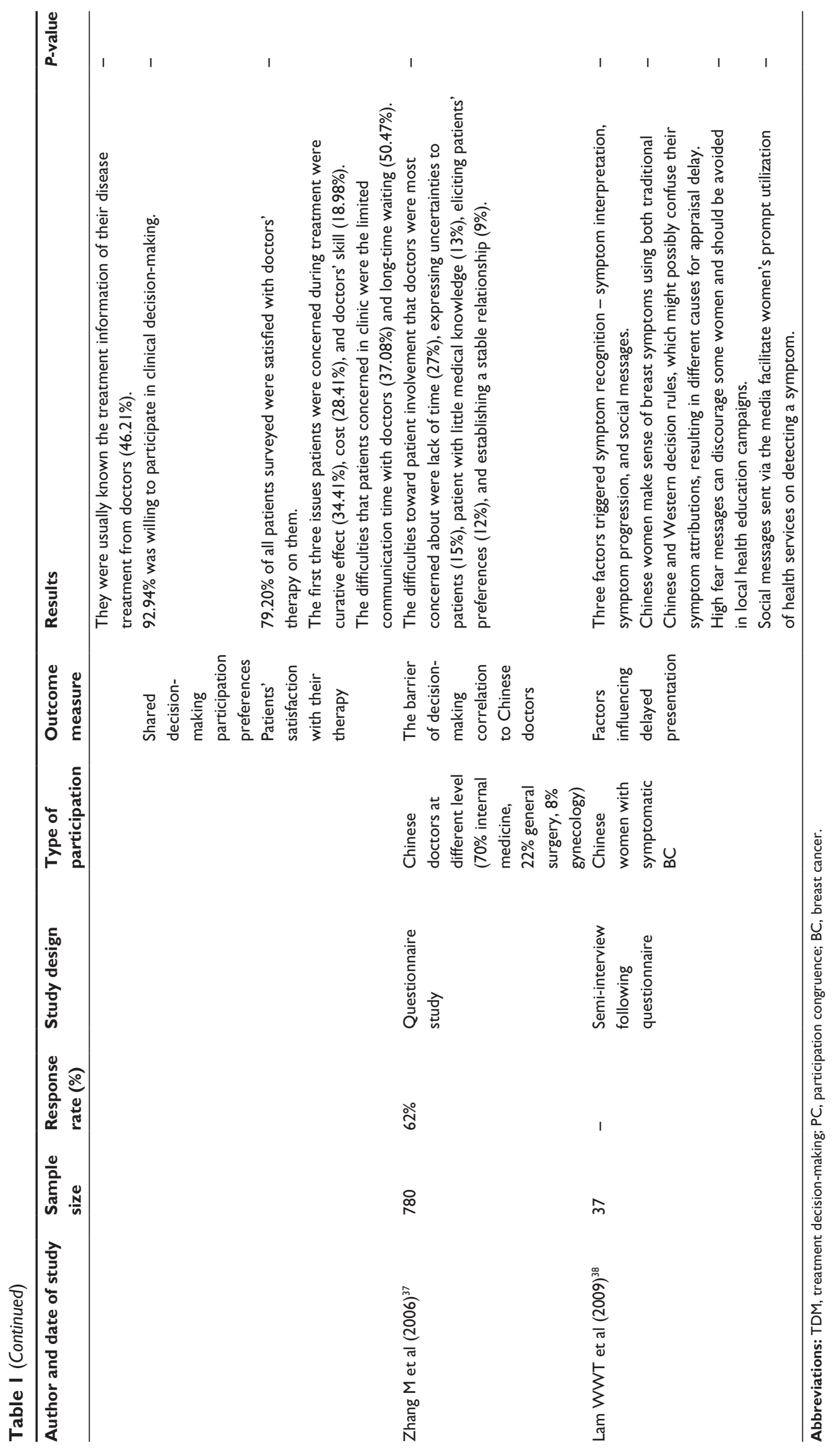




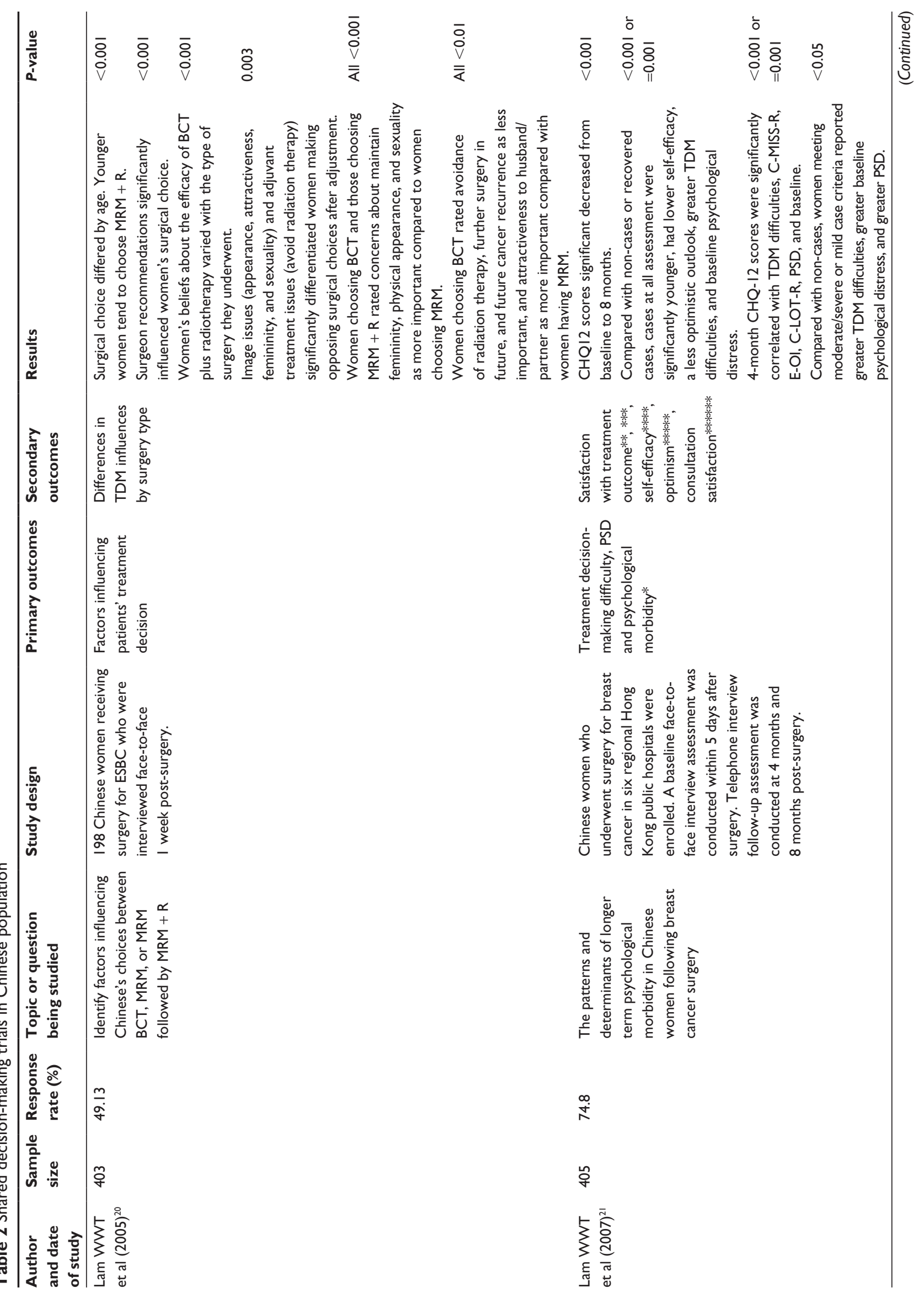




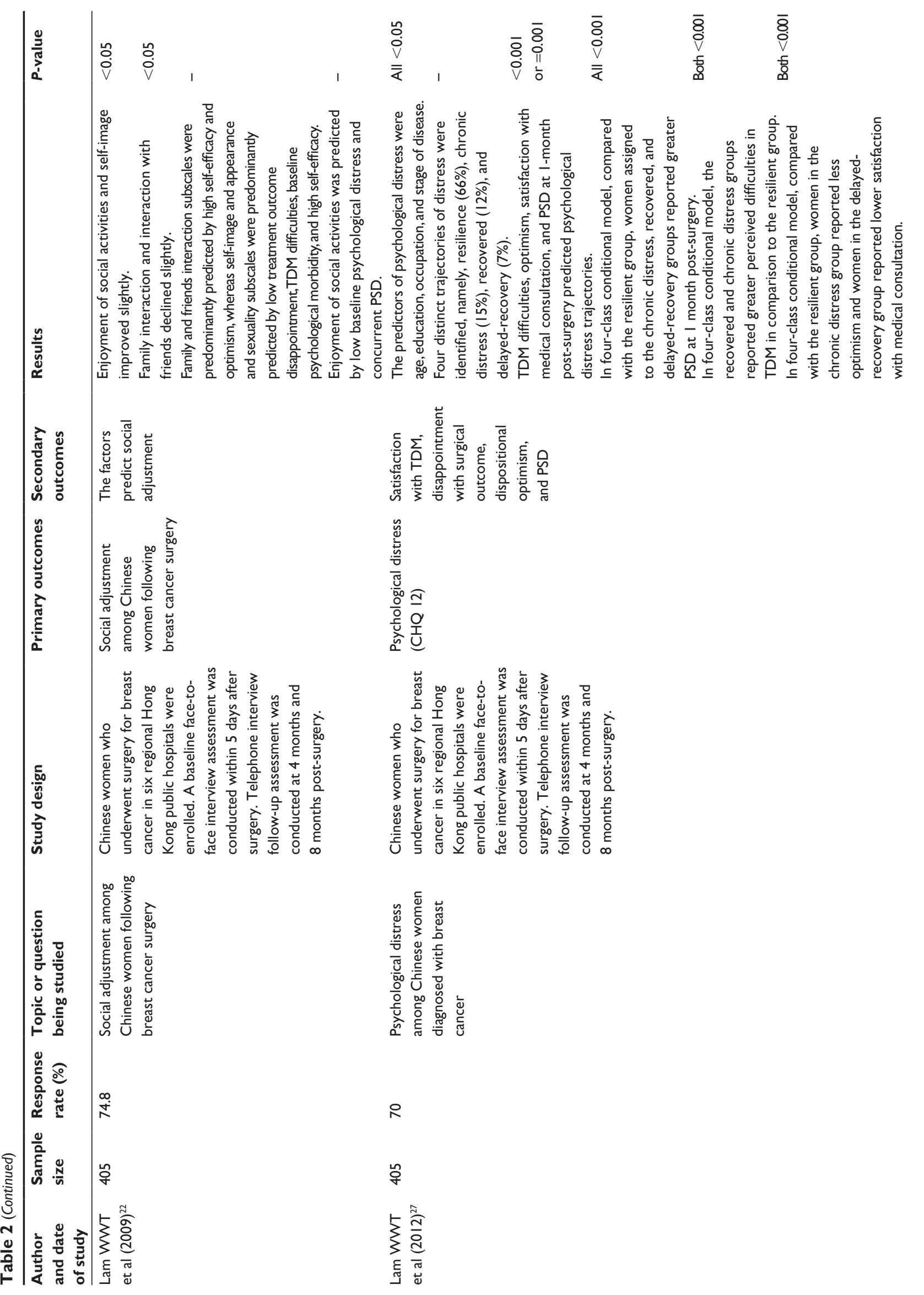




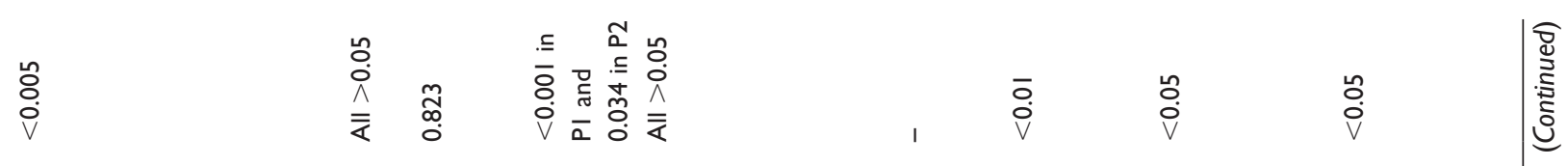

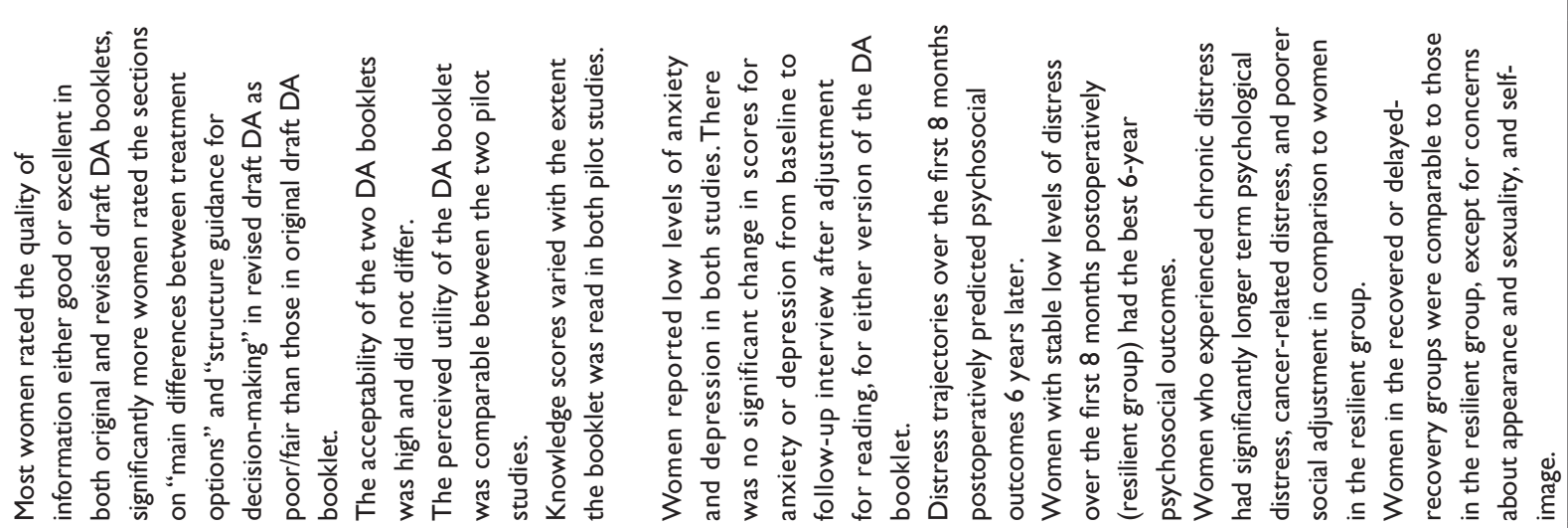

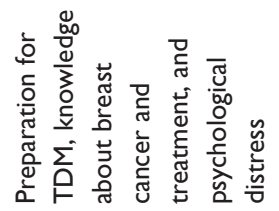

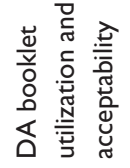
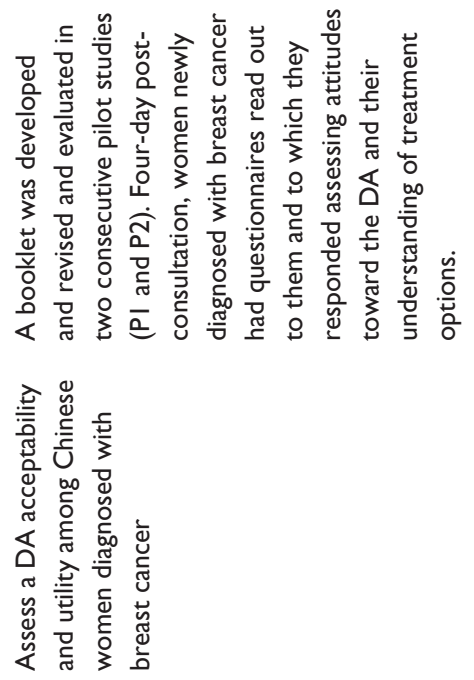

으

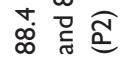

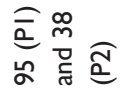

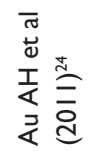
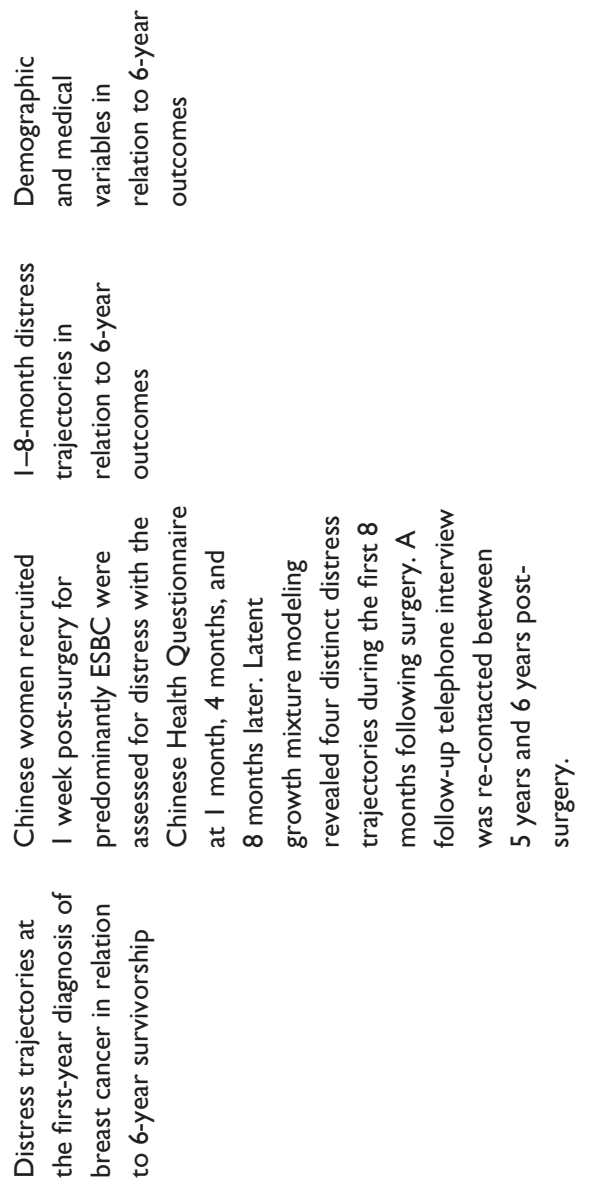

ํํㅇ

ळ్

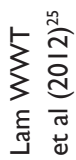




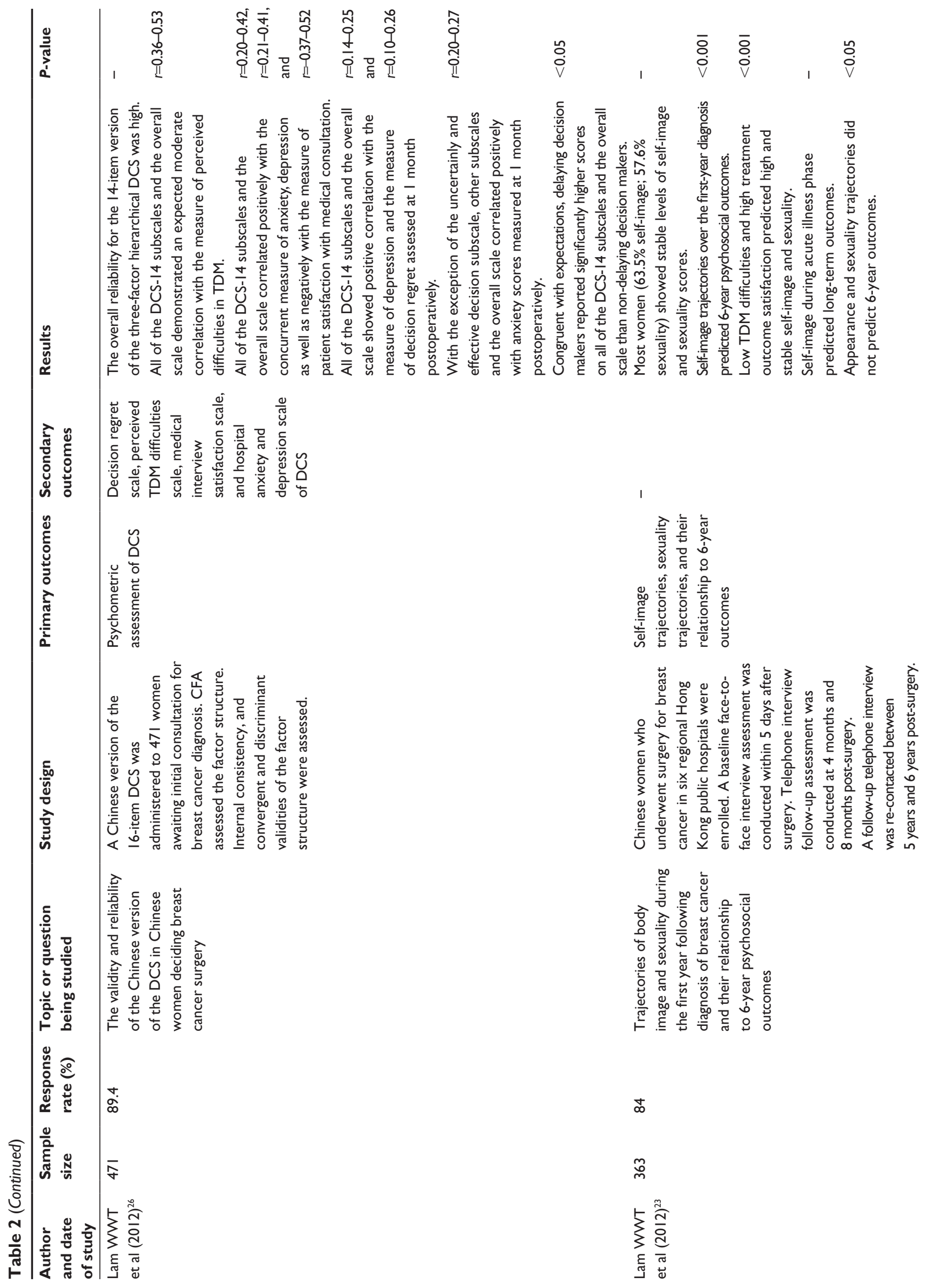




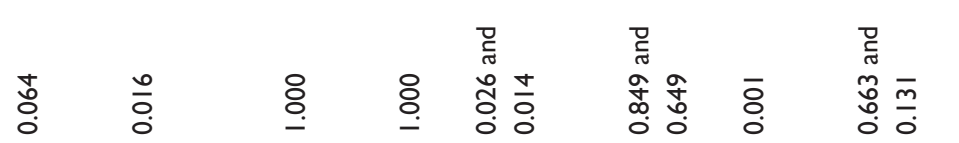

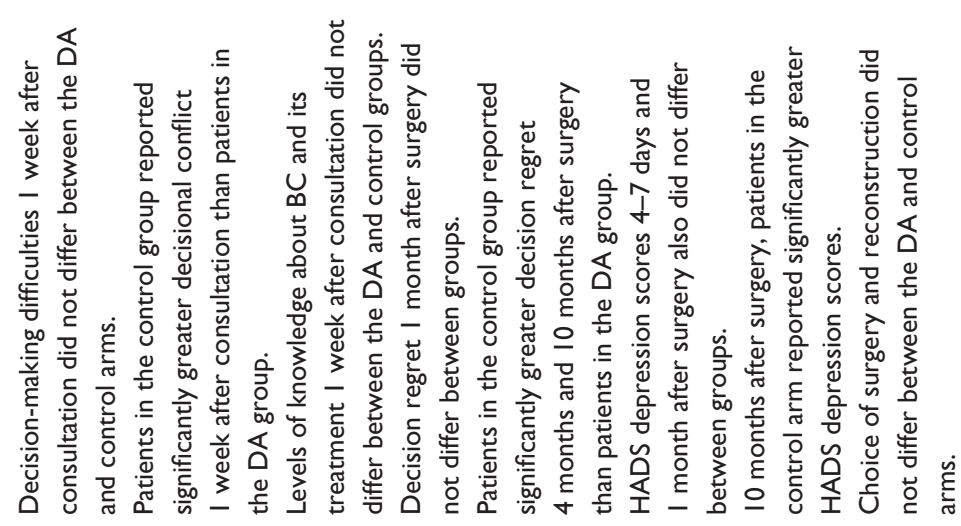

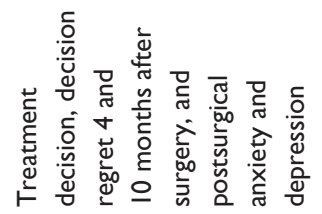
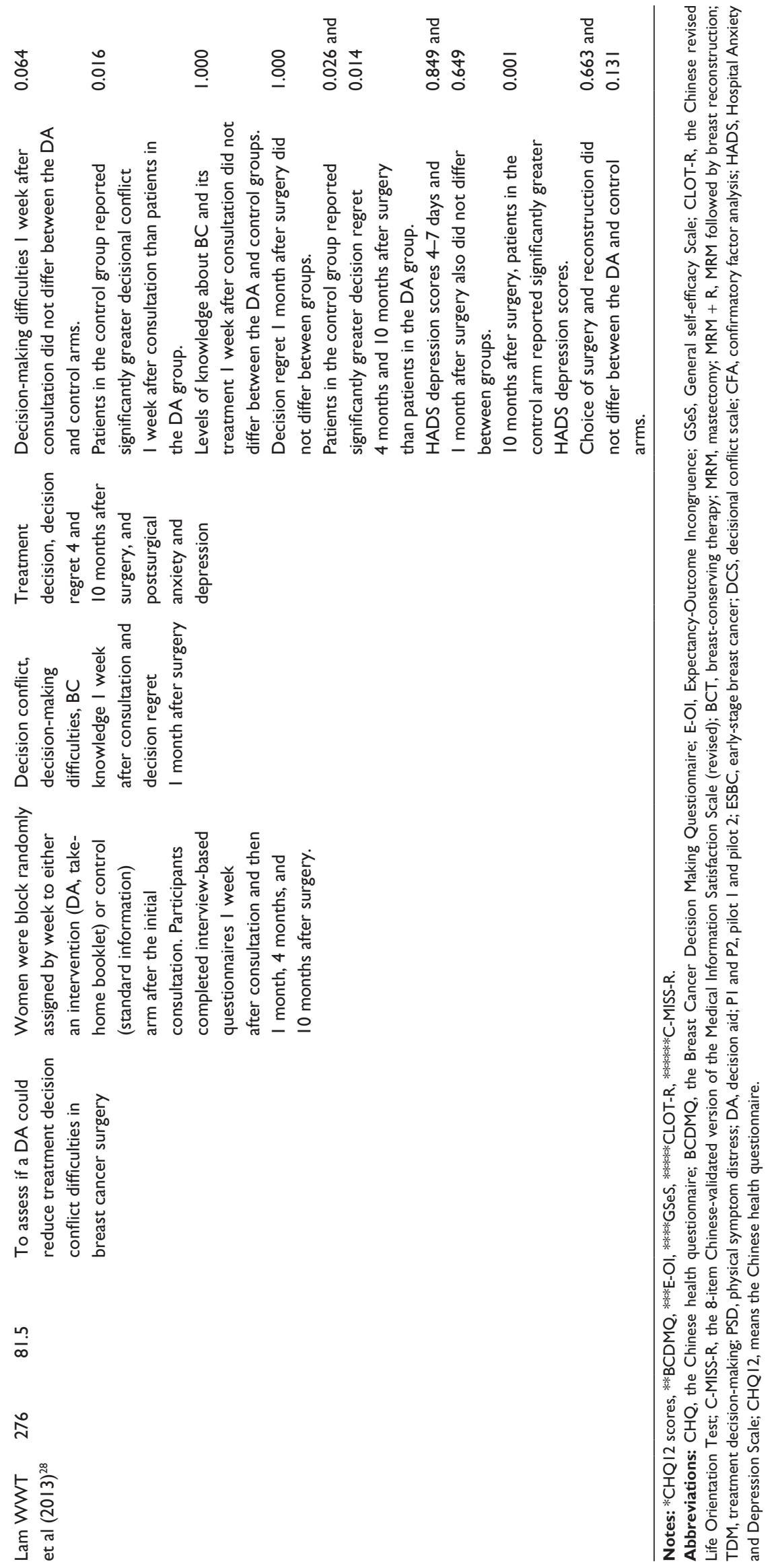
when making decisions about their care. Table 1 shows the results of surveys of Chinese patients' preferences for participation in decision-making, with most studies reflecting the preferences of Chinese people from Hong Kong and these findings are similar to the preferences of patients in North America and Europe. ${ }^{13-18}$

\section{Shared decision-making interventions}

We could not find any studies of SDM tools or interventions developed or tested to promote this process in Mainland China. No data was found related to SDM or decisionmaking in Chinese patients in Mainland China. However, nine studies were found that examined constructs related to SDM among Chinese living in Hong Kong. The population examined in these studies consisted mostly of women with breast cancer. ${ }^{20-27}$ These studies reported on the value of existing measures of decision-making in this population and correlated the quality of decision-making about breast cancer treatment with distress and long-term satisfaction.

\section{Discussion}

\section{Statement of findings}

In this review, we found that little is known and documented about SDM in Mainland China, with very sparse evidence - qualitative or quantitative - about the feasibility, cultural and structural fit, processes, and outcomes of SDM in Chinese patients. We did find that Chinese patients of high socioeconomic status are similar to their counterparts in North America with regard to autonomy and the desire to be involved in medical decisions that affect their lifestyle and outcomes. However, because these respondents do not represent the general population of Mainland China, little is known about the decision-making role preference of patients in Mainland China.

\section{Limitations and strengths}

Almost all participants in the identified surveys must imagine SDM to express preferences for which it reduces the validity of measurement. While this limitation affects nearly all surveys of patient preferences for SDM, this may be more so in the People's Republic of China. This is because the concept of SDM is interpreted differently in various social and cultural contexts. ${ }^{19}$ In the People's Republic of China, medical decisions are often influenced by diverse concepts of social harmony and respect for one's elders, which might be related to different religious or moral codes. An additional barrier to assessing preferences for SDM is disclosing diagnoses to patients with serious diseases, such as cancer, as often both physicians and patient's families avoid telling the patient about serious diagnoses. Therefore, it is difficult to know for sure the extent to which Chinese people would consider SDM, as experienced in North America and Europe, for example, culturally and individually desirable. Most of the available evidence reported here involves Chinese women with breast cancer in Hong Kong. These studies were conducted by the same researchers using small samples and heterogeneous methods. This fuels optimism about the feasibility of SDM in Mainland China.

Yet, due to regional disparities in the People's Republic of China, geographically focused health services and survey research may help determine how best and to what extent patients and clinicians can and will take part in SDM across different health care contexts and across regions in the People's Republic of China. Careful qualitative research to understand how SDM should be understood in the Chinese context may represent an important prerequisite to the empirical task of promoting SDM in the clinical encounter. Such data are not available. Our thorough search strategy, including databases of literature in Chinese, reduces but cannot eliminate the likelihood that we may have missed other studies. To our knowledge, this is the first attempt at systematically summarizing the available literature of SDM in the People's Republic of China and to identify the opportunity gaps in this area.

\section{Implications for policy and practice}

The health care system in the People's Republic of China faces many challenges. The main issue is the lack of sufficient health care resources to meet the needs of its expanding population. There are 260 million patients living with chronic disease. ${ }^{29}$ The People's Republic of China aging population is estimated to increase at a rate of 5.96 million per year from 2001 to 2020. Although the total amount of medical resources per capita has increased, it is still relatively low in the People's Republic of China compared with most developed countries. ${ }^{30}$ This lack of resources coupled with the poor health literacy and unrealistic expectations of patients (eg, expectation for the newest drugs/technologies without understanding of risks/benefits/access limitations) has led to overwhelmed physicians and widespread frustration and dissatisfaction among patients.

For example, in the large hospitals, on average, a physician must treat more than 100 patients every day - this translates to approximately 5 minutes spent with each patient. Consequently, the time for communication is limited; physicians have little time to gather information about the patient 
and to make a diagnosis, to share information about the patient's condition, to share information about the available treatment options, or to share the decision-making process with their patients. This pressure may result in misdiagnoses and low-quality care. Hospitalized patients may find that Chinese physicians are highly skilled in medical techniques, but less skilled in communication. This may be due to the absence of humanities education for medical students in the People's Republic of China. ${ }^{31}$

Given the growing insufficiencies and inequities of the Chinese health care delivery system, low health literacy of the Chinese populations, extremely brief encounters, and the state of distrust and disrespect between patients and clinicians, SDM may not be within reach. Furthermore, cultural differences may require SDM to assume different forms compared to SDM tools and procedures developed in North America, Europe, and Australia. For example, while individual autonomy is typically held as a key bioethical principle, the collectivistic nature of Chinese culture often leads to a decision-making process where the individuals' preferences are informed by and may even be secondary to the preferences of their friends and family. On the other hand, the survey results reviewed here show that Chinese patients of high socioeconomic status are similar to their counterparts in North America with regard to autonomy and the desire to be involved in medical decisions that affect their lifestyle and outcomes. Because these survey respondents did not represent the general population of Mainland China, however, little is known about the decision-making role preference of patients in Mainland China.

Furthermore, the successful implementation of SDM will need support from policy makers, particularly the Chinese government. The Malaysian experience in SDM implementation, a pioneering one in Asia, offers a likely applicable example. ${ }^{32}$ Similar to what we found, very few studies have examined SDM in Malaysia. Existing studies showed that doctors were aware of informed consent, but few practiced SDM. Professional medical bodies endorsed patient involvement in decision-making, but there was no definitive implementation plan. However, the authors have provided a set of recommendations on how SDM can be effectively implemented in Malaysia through education, clinical practice, research, and policy and law. The conditions and culture are similar enough between the People's Republic of China and Malaysia that this experience may apply to Mainland China. Government support may include investments to improve access and quality of care in community settings and better access to and affordability of important evidence-based treatment options, especially in rural areas. In addition to improving the context for SDM to flourish locally, these changes may also promote SDM in the referral urban hospitals by reducing demand for specialized care, resulting in longer appointments.

\section{Implications for research}

While the practice of SDM faces major barriers, research around SDM may be easier to accomplish. Observational studies to understand how decisions are being made across contexts and settings could help establish a baseline and help make the case for SDM. Understanding the professional and patient levers for SDM could also be fruitful. For example, specific and teachable physician-patient communication behaviors, including SDM, are associated with fewer malpractice claims for physicians. ${ }^{33}$ Although the experience from USA may not generalize to the People's Republic of China, because there is no related study in the People's Republic of China, it is worth implementing SDM in the People's Republic of China. Thus, Chinese physicians concerned about the impact of malpractice risk could be motivated to improve their communication skills, in turn promoting the adoption of curricula in SDM and patientcentered communication in medical schools and postgraduate training programs. Medical sociology studies focused on the work of $\mathrm{SDM}^{34}$ may also uncover the roles that patients and clinicians could play. Design researchers could work together with Chinese patients and clinicians to devise cultural- and context-sensitive tools, training, and services that might facilitate SDM, and subject these to empirical testing. Some insights may emerge from the testing of SDM tools developed elsewhere in usual Chinese practice settings, particularly in relation to the division of labor, how practices deal with the demands for decision-making time, how patients respond to the invitation to participate in choice, and how clinicians and patients handle situations in which they disagree.

\section{Conclusion}

While our analysis has focused on Mainland China and its 1.3 billion people, the literature and implications noted here likely apply to the early efforts to promote SDM in low- and middleincome countries with health systems that share the same challenges, if not in magnitude, faced by the Chinese people. In addition to the structural challenges, paucity of research impairs further evidence-based development of SDM in the People's Republic of China, and this needs to be corrected. If successful, SDM may become a more common experience for many patients in the People's Republic of China, which 
could contribute to rebuilding the therapeutic alliance of trust and respect between clinicians and their patients. The health, rights, and respect of vulnerable patients and professionals in the People's Republic of China deserve this transformation.

\section{Acknowledgment}

Michael Gionfriddo was supported by CTSA grant number TL1 TR000137 from the National Center for Advancing Translational Science (NCATS). The contents of this manuscript are solely the responsibility of the authors and do not necessarily represent the official views of the National Institute of Health.

\section{Disclosure}

The authors report no conflicts of interest in this work.

\section{References}

1. Charles C, Gafni A, Whelan T. Shared decision-making in the medical encounter: what does it mean? (or it takes at least two to tango). Soc Sci Med. 1997;44:681-692.

2. Kon AA. The shared decision-making continuum. JAMA. 2010;304: 903-904.

3. Entwistle V. Trust and shared decision-making: an emerging research agenda. Health Expect. 2004;7:3.

4. Peek ME G-BR, Quinn MT, Odoms-Young A, Wilson SC, Chin MH. Patient trust in physicians and shared decision-making among AfricanAmericans with diabetes. Health Commun. 2013;28:8.

5. Mazur DJ, Hickam DH, Mazur MD. The role of doctor's opinion in shared decision making: what does shared decision making really mean when considering invasive medical procedures? Health Expect. 2005;8:97-102.

6. Frosch DL, May SG, Rendle KA, Tietbohl C, Elwyn G. Authoritarian physicians and patients' fear of being labeled 'difficult' among key obstacles to shared decision making. Health Affairs. 2012;31: 1030-1038.

7. Zhong GW. Yi Nao incidents increased by 7,000 over last five years; illegal gangs made huge profits; 2012. Available from: www.china.com.cn/ news/2012-05/03/content_2528733_2.htm. Accessed September 9, 2013.

8. Hesketh T, Wu D, Mao L, Ma N. Violence against doctors in China. BMJ. 2012;345:e5730.

9. Nannenga MR, Montori VM, Weymiller AJ, et al. A treatment decision aid may increase patient trust in the diabetes specialist. The statin choice randomized trial. Health Expect. 2009;12:38-44.

10. Wyatt KD, Stuart LM, Brito JP, et al. Out of context: clinical practice guidelines and patients with multiple chronic conditions: a systematic review. Med Care. 2014;52 Suppl 3:S92-S100.

11. National Research Council. Finding What Works in Health Care: Standards for Systematic Reviews. Washington, DC: The National Academies Press; 2011.

12. Zhang QW WX, Liu Y, Dong XX, et al. A survey analysis of patients' perceptions of difficulties in shared clinical decision-making. Chin J Evid-based Med. 2010;10:3.

13. Mastaglia B, Kristjanson LJ. Factors influencing women's decisions for choice of surgery for stage I and stage II breast cancer in Western Australia. J Adv Nurs. 2001;35:836-847.

14. Whelan T, Levine M, Gafni A, et al. Mastectomy or lumpectomy? Helping women make informed choices. J Clin Oncol. 1999;17: $1727-1735$.

15. Beaver K, Luker KA, Owens RG, Leinster SJ, Degner LF, Sloan JA. Treatment decision making in women newly diagnosed with breast cancer. Cancer Nurs. 1996;19:8-19.
16. Degner LF, Kristjanson LJ, Bowman D, et al. Information needs and decisional preferences in women with breast cancer. JAMA. 1997; 277:1485-1492.

17. Keating NL, Guadagnoli E, Landrum MB, Borbas C, Weeks JC. Treatment decision making in early-stage breast cancer: should surgeons match patients' desired level of involvement? J Clin Oncol. 2002;20: 1473-1479.

18. Bruera E, Willey JS, Palmer JL, Rosales M. Treatment decisions for breast carcinoma: patient preferences and physician perceptions. Cancer. 2002;94:2076-2080.

19. Harter M eG, van der Weijden T. Policy and practice developments in the implementation of shared decision making: an international perspective. German J Evid Qual Healthcare. 2011:5.

20. Lam WW, Fielding R, Ho EY, Chan M, Or A. Surgeon's recommendation, perceived operative efficacy and age dictate treatment choice by Chinese women facing breast cancer surgery. Psychooncology. 2005;14: 585-593.

21. Lam WW, Chan M, Ka HW, Fielding R. Treatment decision difficulties and post-operative distress predict persistence of psychological morbidity in Chinese women following breast cancer surgery. Psychooncology. 2007;16:904-912.

22. Lam WW, Chan M, Hung WK, Or A, Fielding R. Social adjustment among Chinese women following breast cancer surgery. Psychooncology. 2009;18:1189-1198.

23. Lam WW, Bonanno GA, Mancini AD, et al. Trajectories of psychological distress among Chinese women diagnosed with breast cancer. Psychooncology. 2010;19:1044-1051.

24. Au AH, Lam WW, Chan MC, et al. Development and pilot-testing of a decision aid for use among Chinese women facing breast cancer surgery. Health Expect. 2011;14:405-416.

25. Lam WW, Shing YT, Bonanno GA, Mancini AD, Fielding R. Distress trajectories at the first year diagnosis of breast cancer in relation to 6 years survivorship. Psychooncology. 2012;21:90-99.

26. Lam WW, Kwok M, Liao Q, et al. Psychometric assessment of the Chinese version of the decisional conflict scale in Chinese women making decision for breast cancer surgery. Health Expect. 2012.

27. Lam WW, Li WW, Bonanno GA, et al. Trajectories of body image and sexuality during the first year following diagnosis of breast cancer and their relationship to 6 years psychosocial outcomes. Breast Cancer Res Treat. 2012;131:957-967.

28. Lam WW, Chan M, Or A, Kwong A, Suen D, Fielding R. Reducing treatment decision conflict difficulties in breast cancer surgery: a randomized controlled trial. J Clin Oncol. 2013;31:2879-2885.

29. Chinese Center for Disease Control and Prevention (CCDCP). Prevention and Control Work Planning on Chronic Disease in China (2012-2025) (complete version). CCDCP; 2012. Available from: http://www.chinacdc.cn/en/ne/201207/t20120725_64430.html. 2012. Accessed September 9, 2013.

30. Statistics NCfH. Health, United States, 2010: With Special Feature on Death and Dying. Hyattsville, MD: US Government Printing Officer; 2011.

31. Li J, Qi F, Guo S, Peng P, Zhang M. Absence of humanities in China's medical education system. Lancet. 2012;380:648.

32. Ng CJ, Lee PY, Lee YK, et al. An overview of patient involvement in healthcare decision-making: a situational analysis of the Malaysian context. BMC Health Ser Res. 2013;13:408.

33. Levinson W, Roter DL, Mullooly JP, Dull VT, Frankel RM. Physicianpatient communication. The relationship with malpractice claims among primary care physicians and surgeons. JAMA. 1997;277:553-559.

34. Lloyd A, Joseph-Williams N, Edwards A, Rix A, Elwyn G. Patchy 'coherence': using normalization process theory to evaluate a multifaceted shared decision making implementation program (magic). Implement Sci. 2013;8:102.

35. Lam W, Fielding R, Chan M, Chow L, Ho E. Participation and satisfaction with surgical treatment decision-making in breast cancer among Chinese women. Breast Cancer Res Treat. 2003;80: $171-180$. 
36. Lam WW, Fielding R, Chan M, Chow L, Or A. Gambling with your life: the process of breast cancer treatment decision making in Chinese women. Psychooncology. 2005;14:1-15.

37. Zhang MM LJ, Zhang XL, Liu XM, Wang L, He L, Herxheimer A. Doctors' perceptions of difficulties in patient involvement in making treatment decisions: questionnaire study in China. Chin J Evid-based Med. 2006;6:3
38. Lam WWT FR, Chan M, Or A. Factors influencing delayed presentation with symptomatic breast cancer in Hong Kong Chinese women. Hong Kong Med J. 2009;15:3.

\section{Publish your work in this journal}

Patient Preference and Adherence is an international, peer-reviewed, open access journal that focuses on the growing importance of patient preference and adherence throughout the therapeutic continuum. Patient satisfaction, acceptability, quality of life, compliance, persistence and their role in developing new therapeutic modalities and compounds to optimize clinical outcomes for existing disease states are major areas of interest for the journal. This journal has been accepted for indexing on PubMed Central. The manuscript management system is completely online and includes a very quick and fair peer-review system, which is all easy to use. Visit http://www. dovepress.com/testimonials.php to read real quotes from published authors.

\footnotetext{
Submit your manuscript here: http://www.dovepress.com/patient-preference-and-adherence-journal
} 